\title{
GCU
}

Glasgow Caledonian

University

University for the Common Good

\section{Mössbauer and XRD study of AI-Sn linished steel bimetal alloy}

Kuzmann, E.; da Silva, L.; Stichleutner, S.; El-Sharif, M.; Hommonay, Z.; Klencsár, Z.; Sziráki, L.; Chisholm, C.U.; Lak, B.

Published in:

Hyperfine Interactions

DOI:

$10.1007 / \mathrm{s} 10751-016-1363-9$

Publication date:

2016

Document Version

Author accepted manuscript

Link to publication in ResearchOnline

Citation for published version (Harvard):

Kuzmann, E, da Silva, L, Stichleutner, S, El-Sharif, M, Hommonay, Z, Klencsár, Z, Sziráki, L, Chisholm, CU \& Lak, B 2016, 'Mössbauer and XRD study of Al-Sn linished steel bimetal alloy', Hyperfine Interactions, vol. 237, 147. https://doi.org/10.1007/s10751-016-1363-9

\section{General rights}

Copyright and moral rights for the publications made accessible in the public portal are retained by the authors and/or other copyright owners and it is a condition of accessing publications that users recognise and abide by the legal requirements associated with these rights.

Take down policy

If you believe that this document breaches copyright please view our takedown policy at https://edshare.gcu.ac.uk/id/eprint/5179 for details of how to contact us. 


\title{
MÖSSBAUER AND XRD STUDY OF Al-Sn LINISHED STEEL
}

\section{BIMETAL ALLOY}

E. Kuzmann ${ }^{\mathrm{a}}$, L. da Silva ${ }^{\mathrm{b}, \mathrm{c}}$, S. Stichleutner ${ }^{\mathrm{a}, \mathrm{d}}$, M. El-Sharif ${ }^{\mathrm{b}}$, Z. Homonnay ${ }^{\mathrm{a}}$, Z. Klencsár ${ }^{\mathrm{e}}$, L. Sziráki ${ }^{\mathrm{a}}$, C.U. Chisholm ${ }^{\mathrm{b}}$ and G.B. Lak ${ }^{\mathrm{b}}$

\author{
${ }^{a}$ Institute of Chemistry, Eötvös Loránd University, Budapest, Hungary \\ ${ }^{b}$ Glasgow Caledonian University, Glasgow, Scotland, U.K. \\ ${ }^{c}$ MAHLE Engine Systems UK Ltd., Kilmarnock, U.K. \\ ${ }^{d}$ Nuclear Analysis and Radiography Department, Centre for Energy Research, HAS, \\ Budapest, Hungary \\ ${ }^{e}$ Institute of Materials and Environmental Chemistry, Research Centre for Natural Sciences, \\ HAS, Budapest, Hungary \\ e-mail of the corresponding author: kuzmann@caesar.elte.hu
}

\begin{abstract}
Aluminium alloy free CS1 type steel $(0.06 \mathrm{wt} \% \mathrm{C}, 0.45 \mathrm{wt} \% \mathrm{Mn})$ and samples of cold roll bonded steel bimetal alloys (MAS15 and MAS16) were fabricated and investigated by Xray diffraction (XRD), ${ }^{57} \mathrm{Fe}$ conversion electron Mössbauer spectroscopy (CEMS) at room temperature. XRD has revealed only the existence of the alpha iron solid solution (steel) phase in the steel only sample, while identified steel and metallic Al and Sn constituent phases in the bimetallic alloys. ${ }^{57} \mathrm{Fe}$ Mössbauer spectroscopy revealed the presence of $4 \%$ secondary iron-bearing phase attributed mainly to iron oxide/ oxyhydroxides (ferrihydrite) besides the steel matrix on the surface of the steel sample. A significant difference between
\end{abstract}


the occurrences of the secondary phase of differently prepared bimetal alloys found in their ${ }^{57} \mathrm{Fe} \mathrm{CEM}$ spectra allowed to identify the main phase of debris as different iron oxide/ oxyhydroxides.

\section{Keywords}

Lined steel, Al-Sn bimetal alloys, interfaces, Mössbauer spectroscopy, X-ray diffraction

\section{Introduction}

Bearings manufactured from cold roll bonded (CRB) Al/AlSn/Al/ steel composite materials possess superior tribological wear and strength characteristics making them the ideal choice for both passenger car and truck vehicle bearings in the automotive manufacturing industry. The Al-Sn alloy is cold roll bonded to the steel via an aluminium foil (Fig. 1). The aluminium foil surface layer serves to provide a good bonding agent between the aluminium alloy and the steel. However the bearings unique properties can be influenced by the many steps applied during the complex industrial manufacturing process [1]. Steps such as surface preparation and condition, contaminants and oxides formation leading to a possibility of slight changes in elemental composition which could contribute to bond failure.

The aim of the present work was to perform phase analysis in order to elucidate the possible formation of oxide phases at the surface or at the interfaces, when water was sprayed onto the surface of the steel pre cold roll bonding or when linishing debris was deliberately introduced to the surface of the linished steel pre cold roll bonding. 


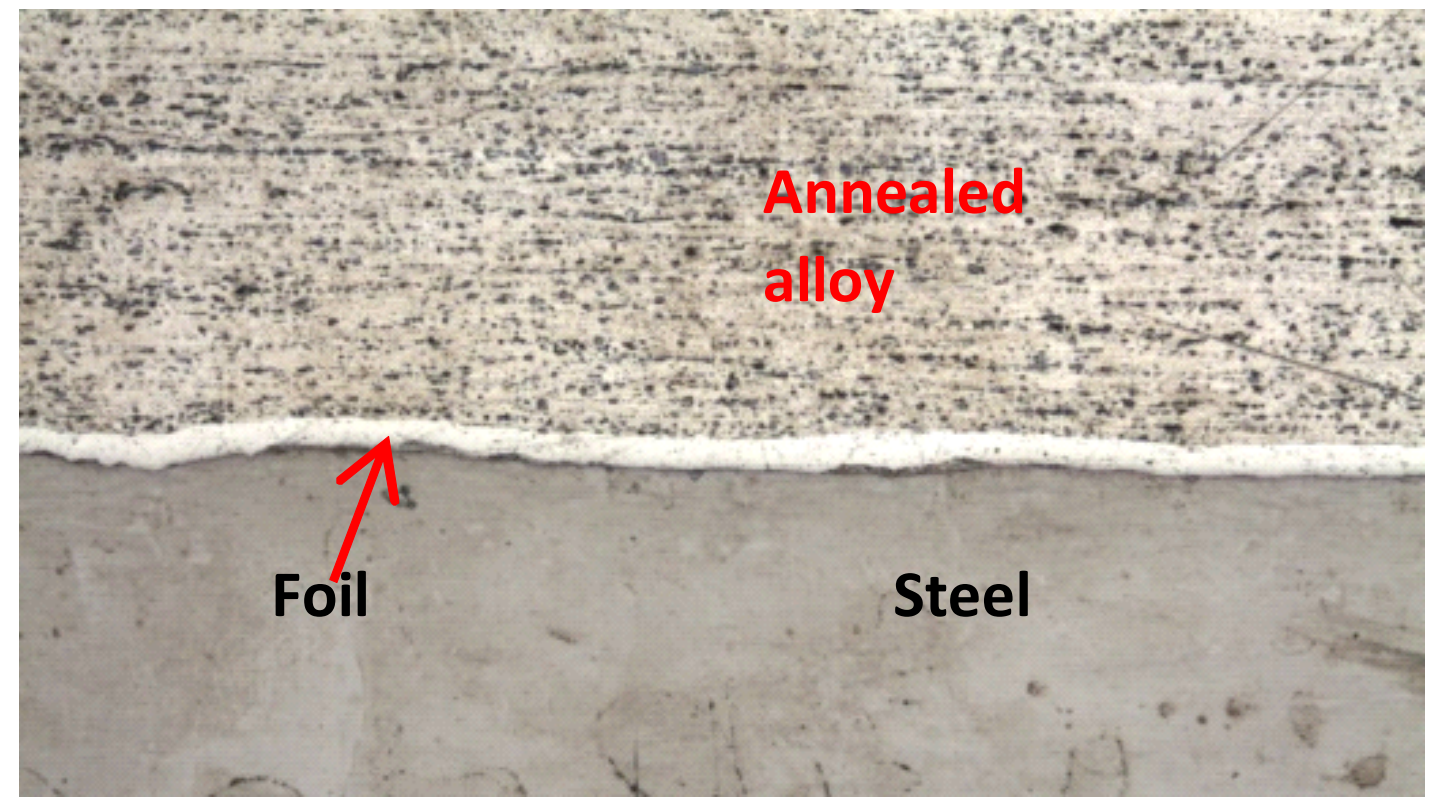

Figure 1. Microsection of an annealed bimetal sample

\section{Experimental}

An aluminium alloy free CS1 type steel $(0.06 \mathrm{wt} \% \mathrm{C}, 0.45 \mathrm{wt} \% \mathrm{Mn})$ and samples of cold roll bonded steel bimetal alloys (MAS15 (Al-20w\%Sn-1w\%Cu) and MAS16 (Al$20 \mathrm{w} \% \mathrm{Sn}-1 \mathrm{w} \% \mathrm{Cu}-0.25 \mathrm{w} \% \mathrm{Mn}))$ were fabricated at different conditions at MAHLE Engine Systems UK Ltd., Kilmarnock, U.K. The characteristics of samples are given in Table 1 and the microsections of samples are shown in Fig. 2. 
Table 1. The characteristics of the samples

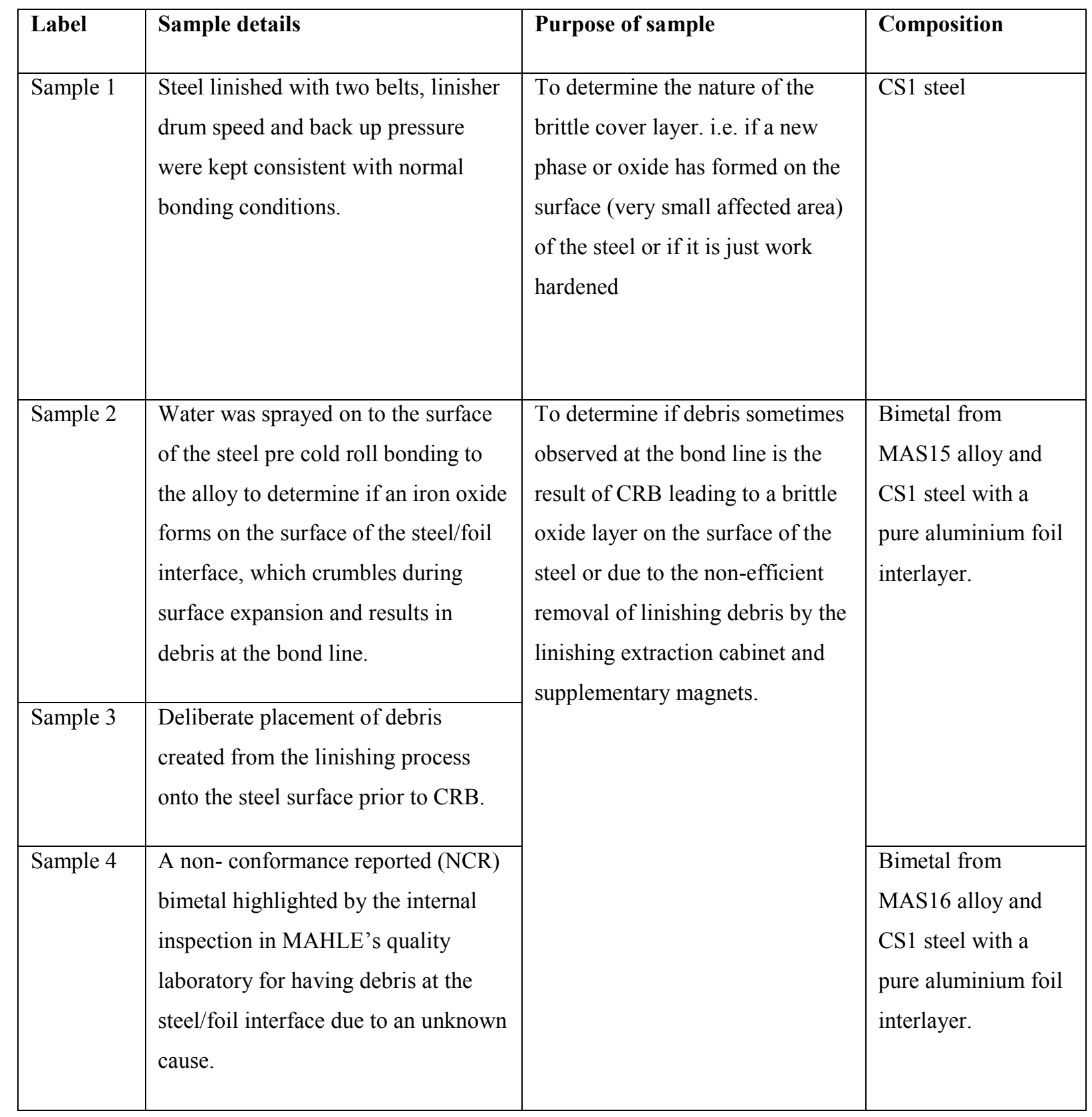



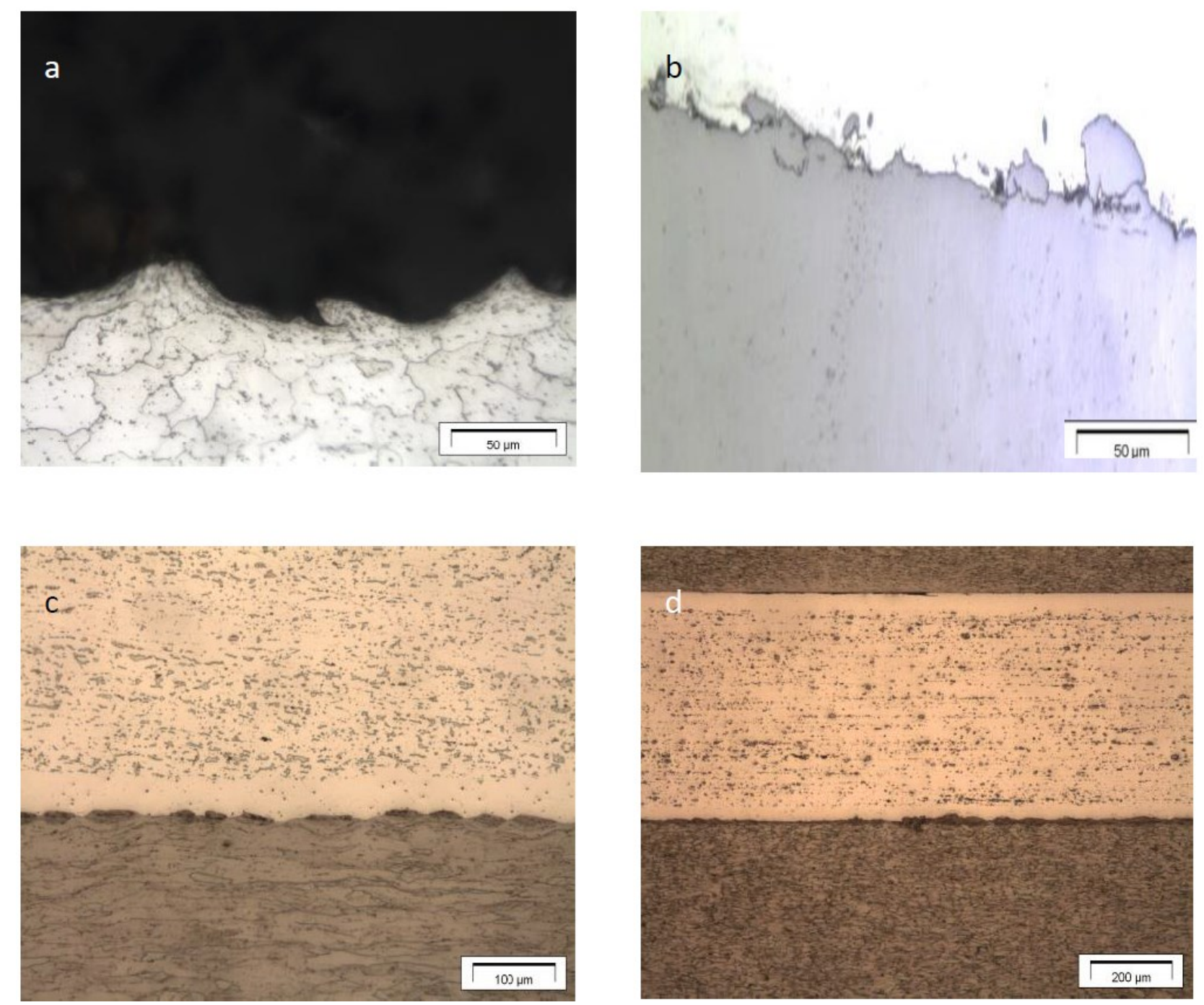

Figure 2. Microsections of samples: (a) sample with linished steel, (b) bimetal sample with deliberate water at the interface, (c) bimetal sample with deliberate linishing debris at the interface and (d) bimetal sample from a non conformance report showing debris at the bond interface.

SEM measurements and the EDX determination of the elemental composition were carried out with a FEI Quanta 3D high resolution scanning electron microscope. 
Powder X-ray diffractograms of the samples were measured in Bragg-Brentano geometry using a DRON-2 computer controlled diffractometer (at $45 \mathrm{kV}$ and $35 \mathrm{~mA}$ ) using the $\beta$ filtered $\mathrm{CuK}_{\alpha}$ radiation $(\lambda=1.54056 \AA)$ at room temperature. The goniometer speed chosen was $1 / 4 \mathrm{deg} \mathrm{min}^{-1}$ in the range of $2 \Theta=10-100 \mathrm{deg}$. The diffraction patterns were evaluated using EXRAY peak searching software. For identification of the phases the ASTM X-ray Diffraction Data were used.

${ }^{57} \mathrm{Fe}$ conversion electron Mössbauer (CEM) spectra of the samples were recorded with conventional Mössbauer spectrometers (WISSEL) working in constant acceleration mode at room temperature. The conversion electrons were detected by a flowing gas RANGER type detector using $\mathrm{He}-4 \% \mathrm{CH}_{4}$ gas mixture. A $50 \mathrm{mCi}$ activity ${ }^{57} \mathrm{Co} / \mathrm{Rh}$ source supplied the gamma rays for ${ }^{57} \mathrm{Fe}$ measurements. The velocity calibration was performed by $\alpha$-Fe measurement. The isomer shifts are given relative to $\alpha$-Fe. The evaluations of the Mössbauer spectra were made by least square fitting of Lorentzian lines using the MOSSWINN software $[2]$.

\section{Results and discussion}

\subsection{X-ray diffraction results}

Powder XRD of samples are shown in Fig. 3. 


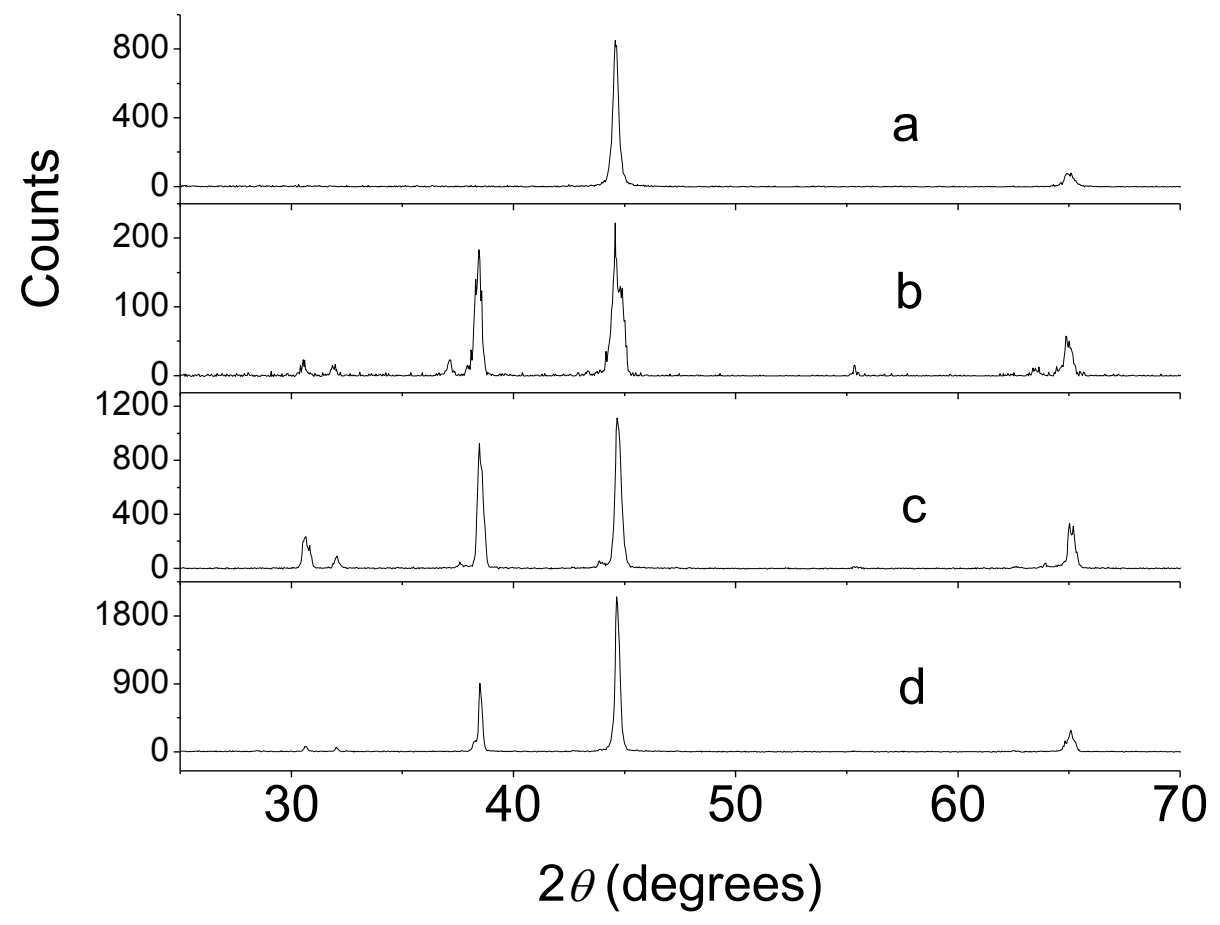

Figure 3. XRD of the samples: (a) linished steel, showing identification of $\alpha$-iron solid solution phase, (b) bimetal sample with water present on the steel surface showing identification of bec $\alpha$-iron solid solution, fcc Al and tetragonal $\beta$-tin, (c) bimetal sample with linishing debris deliberately placed at the bond interface showing identification of bec $\alpha$ iron, fcc Al and tetragonal $\beta$-tin, (d) NCR bimetal sample with unidentified debris at the bond interface showing identification of bec $\alpha$-iron, fcc $\mathrm{Al}$ and tetragonal $\beta$-tin.

All phases where identified using ASTM X-ray diffraction data. The peaks in the Xray diffractogram of sample 1 (linished steel) can be assigned undoubtedly to solid solution of $\alpha-\mathrm{Fe}$ as no other peaks are present in the diffractogram. This is consistent with the XRD pattern you would expect from low alloyed steel. No impurity or oxides were detected in the linished steel sample by XRD. This may however be due to the fact that the penetration depth of the X-rays is roughly $20 \mu \mathrm{m}$ meaning that the above statement, that no oxide or impurity phases were found to be present, is only valid for the bulk material and not for a potential effect on the surface $\sim 0.1 \mu \mathrm{m}$. 
The main peaks in the X-ray diffractograms of bimetal samples 2, 3 and 4 can also be undoubtedly assigned. The main peaks in all 3 samples were assigned to bcc $\alpha-\mathrm{Fe}$, fcc $\mathrm{Al}$ and $\beta$-Sn. This is consistent with the samples analysed as the main compositions of bimetal samples 2, 3 and 4 is aluminium, steel and incorporated tin. The effect of alloying elements such as $\mathrm{Mn}$ and $\mathrm{Cu}$ however, have not clearly been detected in the diffractograms.

\subsection{Mössbauer results}

The Mössbauer spectra of samples are shown in Figs. 4-7. The Mössbauer parameters are depcted in Table 2.

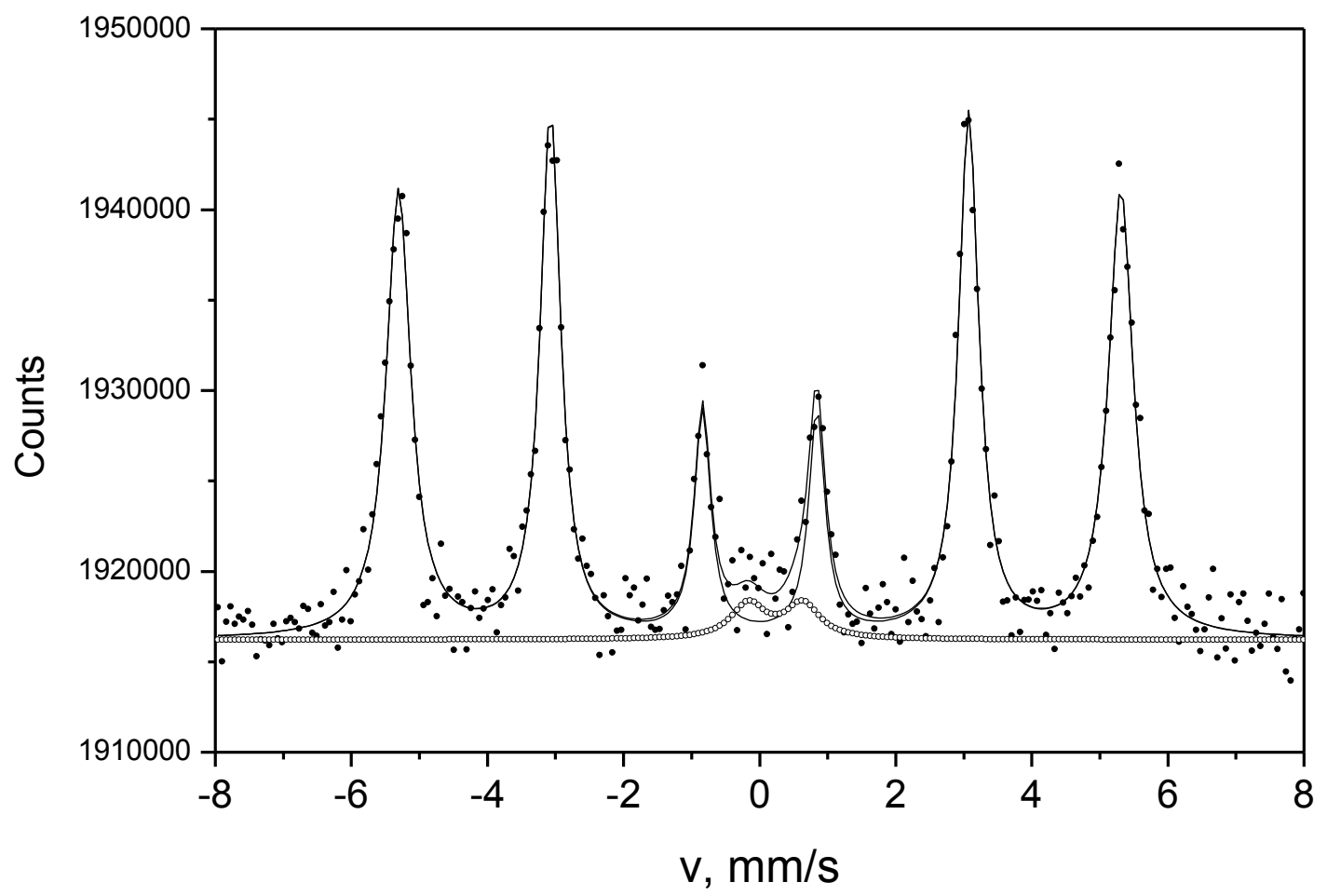

Figure 4. ${ }^{57} \mathrm{Fe}$ CEM spectrum of sample 1, linished steel 


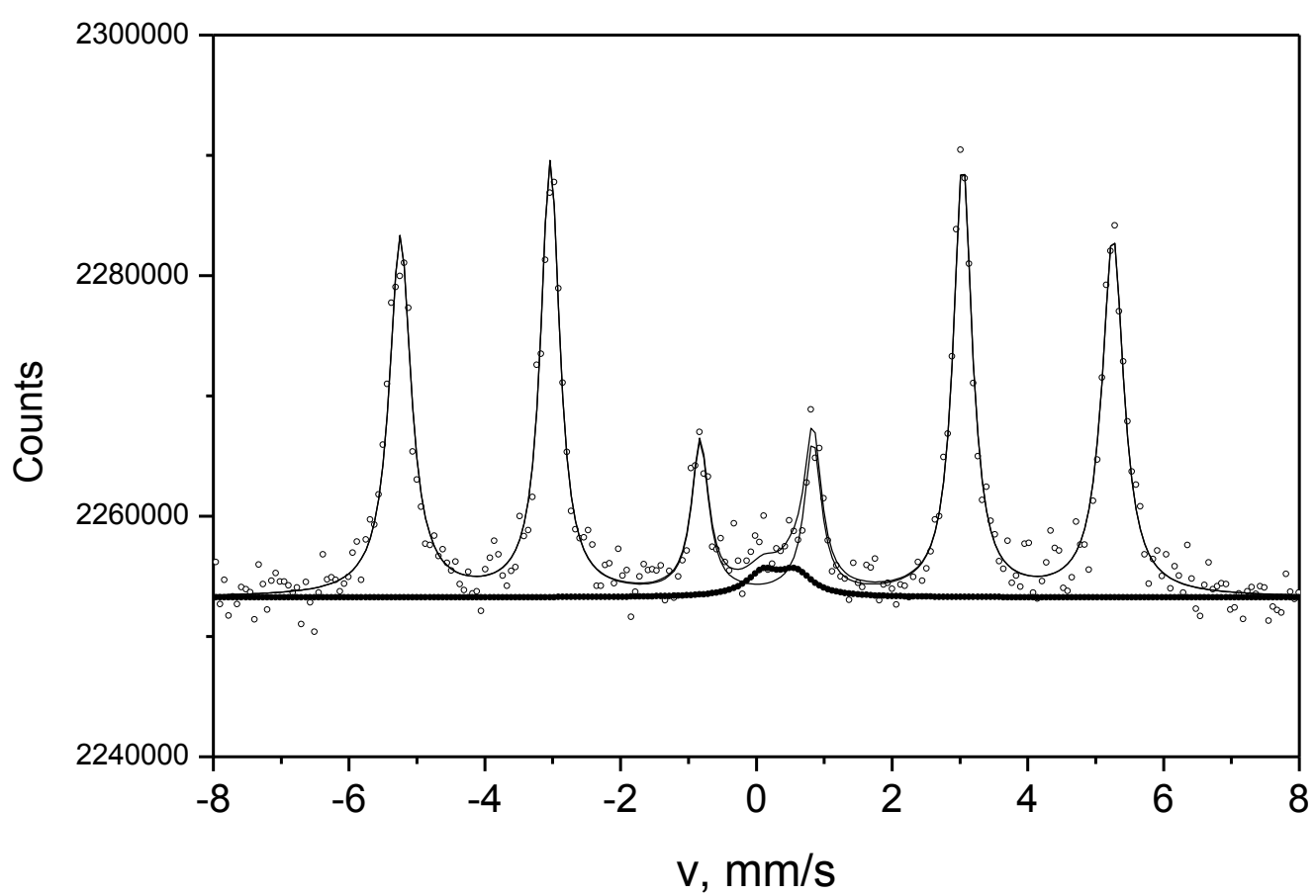

Figure $5 .{ }^{57} \mathrm{Fe} \mathrm{CEM}$ spectrum of sample 2, water spray

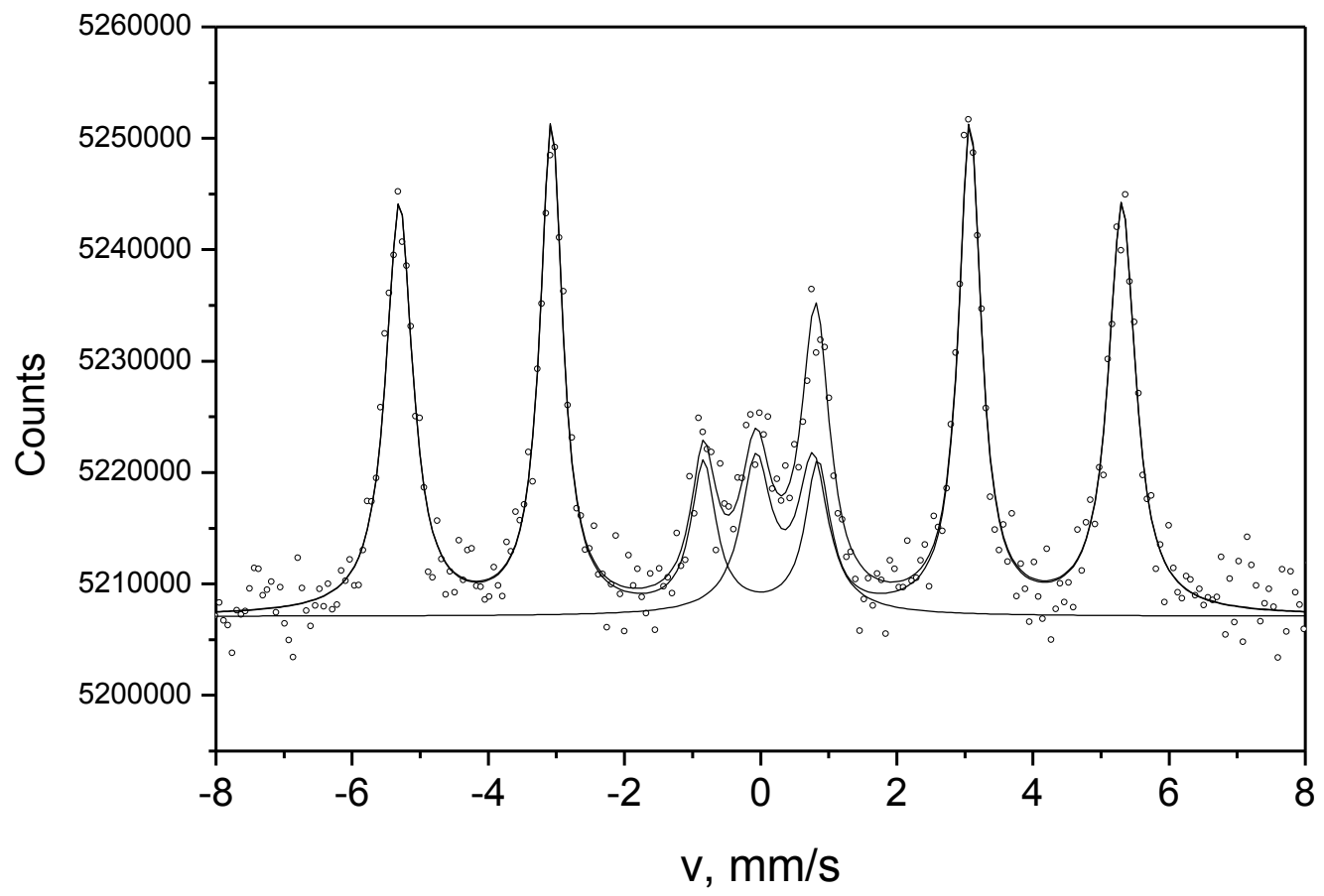

Figure $6 .{ }^{57} \mathrm{Fe}$ CEM spectrum of sample 3, deliberate debris 


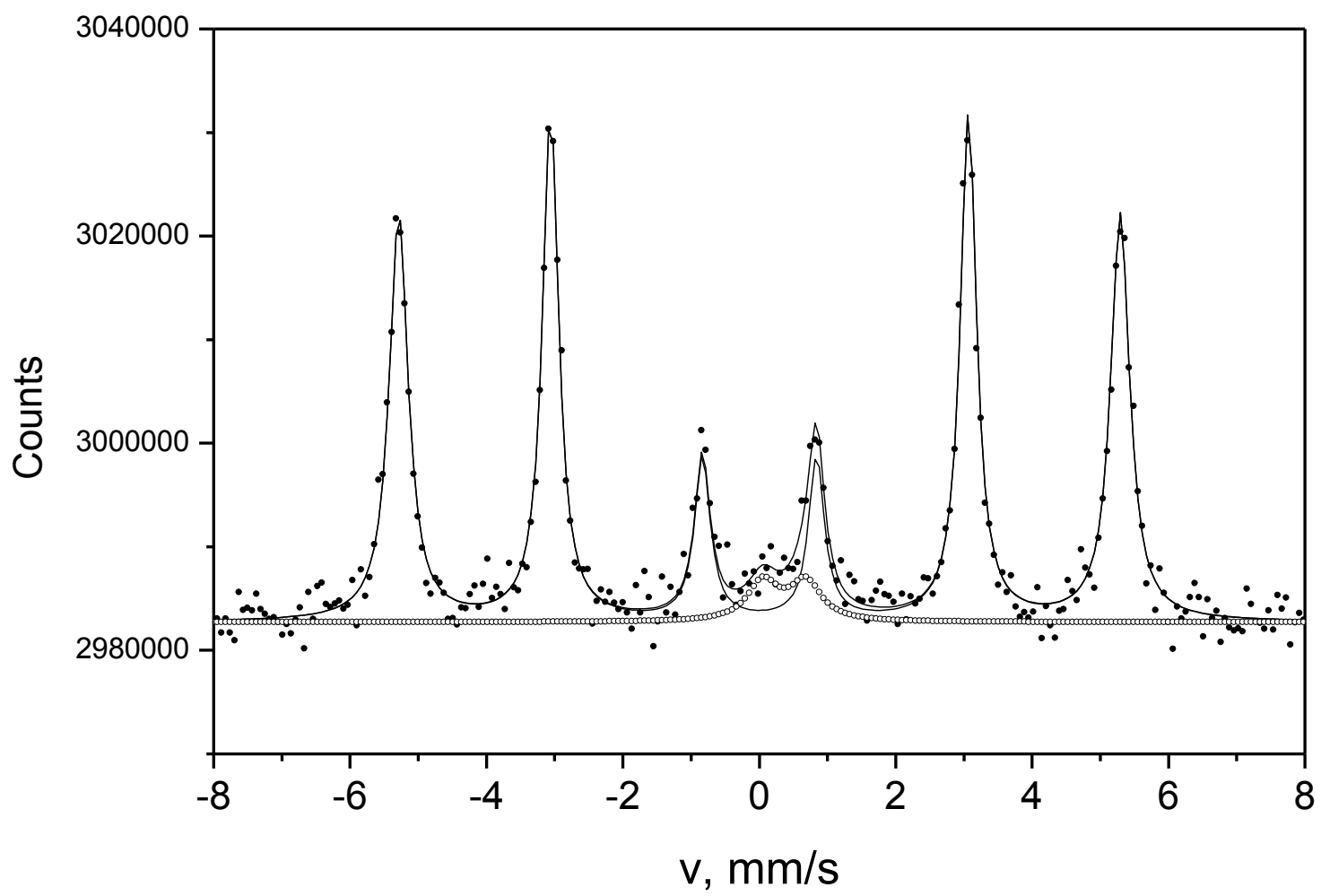

Figure 7. ${ }^{57} \mathrm{Fe}$ CEM spectrum of sample 4, NCR bimetal

Table 2. ${ }^{57} \mathrm{Fe}$ Mössbauer parameters of the samples

\begin{tabular}{|l|l|l|l|l|}
\hline & Sample 1 & Sample 2 & Sample 3 & Sample 4 \\
\hline Sextet & & & & \\
\hline A $(\%)$ & 96.0 & 96.1 & 85.0 & 93.8 \\
\hline$\delta(\mathrm{mm} / \mathrm{s})$ & $0.0 \pm 0.003$ & $0.0 \pm 0.003$ & $0.0 \pm 0.003$ & $0.0 \pm 0.003$ \\
\hline$B(\mathrm{~T})$ & $33.0 \pm 0.025$ & $33.0 \pm 0.023$ & $32.99 \pm 0.029$ & $33.0 \pm 0.022$ \\
\hline Doublet & & & & \\
\hline A $(\%)$ & 4.0 & 3.9 & 15.0 & 6.2 \\
\hline$\delta(\mathrm{mm} / \mathrm{s})$ & $0.34 \pm 0.005$ & $0.34 \pm 0.005$ & $0.35 \pm 0.007$ & $0.35 \pm 0.007$ \\
\hline$\Delta(\mathrm{mm} / \mathrm{s})$ & $0.78 \pm 0.10$ & $0.47 \pm 0.09$ & $0.82 \pm 0.06$ & $0.63 \pm 0.08$ \\
\hline
\end{tabular}


The main sextet in ${ }^{57} \mathrm{Fe}$ Mössbauer spectrum of sample 1 is the fingerprint of solid solution $\alpha$-Fe, corresponding to the sextet illustrated in Fig. 4 and well expected for the very low alloyed CS1 steel. A minor doublet also appears in the Mössbauer spectrum. The Mössbauer parameters of this doublet subspectrum can be associated with paramagnetic (or superparamagnetic) iron oxides or iron oxyhydroxides [3], most probably with the so called "amorphous oxide", ferrihydrite. This is in keeping the findings of Ganguly et al [4]. Ferrihydrite has already been identified as corrosion product on the surface of steels under various circumstances [5-7]. These phases can often be formed on the surface of iron in air or under corrosive conditions. Mössbauer spectroscopy reveals that less than $4 \%$ iron oxide/oxyhydroxide is present on the very surface (below $0.1 \mu \mathrm{m}$ ) of the linished steel sample.

The main sextet component in the ${ }^{57} \mathrm{Fe}$ CEM spectra of the bimetal samples can also be undoubtedly identified. In all spectra of the bimetal samples (samples 2, 3 and 4) the main sextet is again well assigned to solid solution $\alpha$-Fe, reflecting the steel component in the bimetal alloys. Since the ${ }^{57} \mathrm{Fe}$ Mössbauer spectroscopy can monitor only iron-bearing phases the MAS15 or MAS16 alloys and pure Al foil interlayer cannot be directly seen in the ${ }^{57} \mathrm{Fe}$ spectra.

A minor doublet component is also present in all ${ }^{57} \mathrm{Fe}$ CEM spectra of the bimetal samples. This component can be assigned again mainly to the paramagnetic (or superparamagnetic) iron oxides or iron oxyhydroxides [3]. The slight difference in quadrupole splitting of the doublet between sample 2 as compared to samples 1, 3 and 4 indicates a difference in the asymmetric electronic charge distribution due to a potentially differing ligand arrangement that results in different splitting. This shows that although water spray on the steel surface prior to $\mathrm{CRB}$ can result in oxide formation at the $\mathrm{Al} / \mathrm{steel}$ interface it is a different oxide composition or structure to that of the oxide phases present at the bond line in samples 1,3 and 4 . The isomer shift of the doublets however suggests that the same iron ion is present in all 4 oxides. Therefore the NCR bimetal must have occurred from excess linishing debris present at the bond interface. Additionally, significant differences were observed between the occurrences of iron-oxide/oxyhydroxides in the different bimetal alloys. About $4 \%$ of this phase was detected for both sample 1 (the linished steel) and sample 2 (the water spray), while the content of the iron oxide/oxyhydroxide phases is as high as 
$15 \%$ in sample 3 (the deliberate debris) and $6 \%$ in sample 4 (the NCR bimetal). Since the debris is present in a more concentrated form in sample 3, this was used to assign the major phase of the debris to iron oxide/oxyhydroxides, especially to ferrihydrite whose poor crystalline "amorphous" character would be consistent with the fact that these phases could not be detected in the XRD analysis. The relatively high percentage amounts of this phase detected for sample 3 is purely due to an excessive amount of debris deliberately placed on the steel surface to exaggerate the effect at the bond interface.

Ferrihydrite, a naturally occurring compound, is regarded as one of the eight major iron oxide/oxyhydroxides [8]. Its exact structure is still a matter of controversy within the literature. Due to its poor crystallinity it is difficult to obtain its structure by X-ray diffraction. A number of formulae have been proposed such as $5 \mathrm{Fe}_{2} \mathrm{O}_{3} .9 \mathrm{H}_{2} \mathrm{O}$ [9], $\mathrm{Fe}_{5} \mathrm{HO}_{8} .4 \mathrm{H}_{2} \mathrm{O}$ (Towe and Bradley [10]) and $\mathrm{Fe}_{2} \mathrm{O}_{3} \cdot 2 \mathrm{FeOOH} \cdot 2.6 \mathrm{H}_{2} \mathrm{O}$ (Russell [11]). These formulae can be considered equivalent and can be reduced to $\mathrm{FeOOH} .0 .4 \mathrm{H}_{2} \mathrm{O}$, a hydrated iron oxyhydroxide. Zhao et. al [12] conducted a study on ferrihydrite that used XRD, TEM, X-ray absorption fine structure (XAFS) and Mössbauer spectroscopy performed at a temperature of $12 \mathrm{~K}$ that showed evidence of coordination unsaturated sites, believed to be tetrahedral, and present at the surface of the ferrihydrite. It may therefore be that when water is present at the surface of the steel chemisorption takes place and introduces a hydroxide ligand to the available coordination unsaturated site. This extra ligand would thus change the asymmetric electronic charge distribution accounting for the difference in quadrupole splitting for the sample with water present on the steel surface. This would also account for the ionic charge on the iron remaining the same and thus not affecting the measured isomer shift for sample 3.

If a ferrihydrite phase is present on the steel surface it can prevent nascent dissimilar metal contact and thus result in reduced bond strength. Some authors (e.g. Quadir et al [13]) believe the oxide layer to function as the brittle cover layer and aid bonding due to its brittle, high hardness value, causing the oxide layer to crack readily exposing nascent material underneath. However this only appears to be the case when the oxide layer described is thick due to anodization, as atmospheric oxidation has been reported to reduce bond strength $[14,15]$. This study shows that of the about $1000 \AA$ of the steel surface (monitored by the CEMS) only $4 \%$ of the linished steel comprised of an iron oxide/oxyhydroxide, which would not be enough, alone, to account for the cracks that appear in the surface of the steel during CRB. Therefore the key factor in facilitating a good bond by nascent metal exposure is by sufficiently work hardening the surface to obtain a brittle cover layer. 


\section{Conclusions}

$\mathrm{XRD},{ }^{57} \mathrm{Fe}$ conversion electron Mössbauer characterisations on CS1 type steel and differently treated cold roll bonded steel bimetal alloys (MAS15 and MAS16) led to the following conclusions:

- XRD results showed that the steel only sample is a solid solution of $\alpha$-Fe and no other peaks are present in the diffractogram which suggests that no impurity or oxides were formed in the sample. The main peaks in the X-ray diffractograms of all investigated bimetal samples can be well assigned to a solid solution $\alpha-\mathrm{Fe}$, fcc $\mathrm{Al}$ and $\beta$-Sn as it was expected from the main compositions of these bimetal samples.

- ${ }^{57} \mathrm{Fe}$ Mössbauer spectra of all samples consist of a dominant solid solution $\alpha$-Fe sextet. A minor doublet also appears in all the ${ }^{57} \mathrm{Fe}$ Mössbauer spectra, which could be associated with paramagnetic iron oxides or iron oxyhydroxides, accordingly to that these phases can often be formed on the surface of iron in air or under different corrosive conditions.

- Significant differences in the observed amount of iron-oxide/oxyhydroxides in the different bimetal alloy samples presented. Additionally, the slight difference in quadrupole splitting of the ${ }^{57} \mathrm{Fe}$ doublet between the differently prepared samples could indicate a difference in the microenvironments of Fe. Since the material of debris was not in the scope of the current study, it is uncertain whether the linishing process create the iron-oxide/oxihydroxides present in a more concentrated form in sample when linishing debris was deliberately introduced to the surface of the linished steel pre cold roll bonding, or the cold roll bonding process itself. However, if an iron-oxide/oxihydroxide phase is present on the steel surface, it could prevent nascent dissimilar metal contact and thus could result in reduced bond strength of the bimetal alloy leading to material failure in a form of delamination.

\section{Acknowledgements}

Financial support from the Hungarian National Research Fund (OTKA project No K68135 K115913) is gratefully acknowledged. 


\section{References}

[1] da Silva L., Technical Report KTP 01003, MAHLE Engine Systems UK Ltd., Kilmarnock, 2012.

[2] Klencsár, Z. Kuzmann, E. Vértes, A. J. Radioanal. Nucl. Chem. 210 (1996) 105.

[3] Stevens, J.G., Stevens, V., Mössbauer Reference and Data Index, 1966-1978. Plenum Press, New York.

[4] Ganguly, B., Huggins, F.E., Feng, Z. and Huffman, G.P. Physical Review B, 49, (1994) 3036-3042.

[5] Furukawa,Y., Kim, J.-W., Watkins, J. Wilkin, R. T., Environ. Sci. Technol., 36 (2002) $5469-5475$.

[6] Nakanishi, A., Kobayashi T., Hyperfine Interact. 156/157 (2004) 493-496.

[7] Agudelo, A.C. Marco, J.F. Gancedo, J.R. Perez-Alcazar, G.A., Hyperfine Interact. $139 / 140(2002) 141-152$.

[8] Schwertmann, U. und R. M. Cornell: Iron Oxides in the Laboratory - Preparation and Characterization. VCH Verlagsgesellschaft, Weinheim 1991.

[9] Fleischer, M., G. Y. Chao, and A. Kato. Am. Mineral. 60 (1975) 485-486.

[10] Towe, K. M. and W. F. Bradley. J. Colloid Interface Science 24 (1967) 383-392.

[11] Russell, J. D. Clay Miner. 14 (1979) 109-113.

[12] Zhao, J., Huggrns, F. E., Feng, Z., Huffman G. P., Clays and Clay Minerals, 42 (1994) 737-746.

[13] Quadir, M.Z., Wolz, A., Hoffman, M., Ferry, M. Scripta Materialia, 58 (2008) 959-962. 
[14] Krallics, G., Lenard, J.G. Mater. Sci. 15 (2004) 2483-2488.

[15] Le, H.R. Sutcliffe, M.P.F. Wang, P.Z. Burstein G.T. Applied Science and Manufacturing 35 (2004) 637-643. 